\title{
Research on the Spatial and Temporal Structure Evolution of Inbound Tourism in Hainan Province
}

\author{
Bao Fuyuan \\ School of International Hospitality Management, University of Sanya \\ Sanya, China 572022
}

\begin{abstract}
To promote the development of inbound tourism market in Hainan province, it is essential to explore the spatial and temporal structure evolution of inbound tourism. This paper compares the seasonal intensity index of the past years, summarizes the years in which the inbound tourism of Hainan Province has experienced a significant fluctuation during the low and peak seasons, and calculates the monthly average index to categorize low season, high season and shoulder season. And the deviating geographical concentration index of Hainan in years 2008 to 2016 showed that the concentration degree of inbound tourism in Hainan was fluctuating irregularly. According to the changes of spatial and temporal structure, it is suggested to provide various types of tourism products, carry on effective marketing activities to attract emerging tourist market and promote the development of inbound tourism in Hainan.
\end{abstract}

Keywords-Inbound tourism; Seasonal intensity index; Geographic concentration index; Monthly average index

\section{INTRODUCTION}

Developing inbound tourism market is an important target of developing tourism in Hainan international Tourism Island. The scale of inbound tourism has been shrunken dramatically in recent years in Hainan due to the influence of the global financial crisis. Although a certain recovery has been achieved, the growth rate has been slow. The research on the evolution of the spatial and temporal structure of the inbound tourism in Hainan and analysis on the change of the inbound tourism during the low season and peak season and the change of the tourist source concentration degree in Hainan will be conductive to carrying out targeted product supply and marketing publicity. There have been rich research achievements on the spatial and temporal structure of inbound tourism, the spatial and temporal structure is the main field for the research on the inbound tourism market, the early foreign researches cover the seasonal definition, causes, countermeasures, demand differences and other aspects (Baron, 1975; Mark, 1992; Muzaffe (1994) [1-3] of tourism, the perspectives of foreign research has tended to be diversified after entering the $21 \mathrm{st}$ century, including questionnaire surveys and interview method analysis to respond to the problems of tourism during the low season and peak season (Donald, 2004) [4], telephone interviews on the characteristics of tourism and the cluster analysis (Daniel, 2007) [5], and the research methods mainly include quantitative analysis method in combination with the latest technologies such as TRAMO-SEATS and X-12-ARIMA technology (Erdogan, 2007) [6], spectrum analysis method (Felix, 2011) [7], ratio-to-moving average (Christine Lim, 2005) [8], seasonal intensity index, etc. The foreign researches on the inbound tourist source market have also been shifted from the basic characteristics and law description to the interpretation of the dynamic law of the inbound tourism market, and the research methods have been gradually improved. The researches on the seasonality of tourist flows in China focus on the analysis of seasonality causes and countermeasures. Bao Jigang (1999) proposed the seasonal tourism problems more early, and then He Xiaorong (2001) proposed the patch of balancing the seasonality [10]. Simultaneously, the comparative analysis on the seasonality between the tourism destinations of the same types is another content of the seasonality research. Zhang Jie (1999) compared and analyzed the types, characteristics and related geographical structures [11] of tourism flow time distribution between the tourism destinations, Lu Lin (2002) compared the seasonal characteristics of tourism flows between seaside tourism destinations and mountain tourism destinations [12], and Zhong Jing (2007) conducted a comparative research on the seasonal characteristics of tourism flows in historical and cultural villages and towns [13]. The researches on seasonal changes of inbound tourism mainly focus on inter-annual changes and seasonal characteristics. The analysis by Chai Shousheng (2007) showed that the seasonal intensity index of inbound tourism from 2000 to 2005 in Qingdao was continuously decreased and the time distribution of inbound tourism demand became more and more uniform [14]; The analysis on the seasonal characteristics of the foreign tourist source market for inbound tourism in China by Zhong Jing (2008) showed that the inter-annual changes was not significant [15]; Jiang Guohua (2016) [16] and Liao Qin (2013) [17] conducted a continuous analysis on the changes in the seasonal intensity indexes of inbound tourism in Shanghai; In terms of the research on the seasonality of inbound tourism in Hainan, Su Peng (2010) [18], Chen Yun and Tian Liang (2013) [19] calculated the seasonal intensity indexes of inbound tourism in Hainan respectively; There were a few new concerns about the researches on the time sequence differences between different regional scales of inbound tourism in China (Wang Qin'an, 2017) [20]. Among the research methods, most of the comparisons of the inter-annual changes in inbound tourists during the low season and peak season are mainly based on the annual calculation of the 
seasonal intensity index $\mathrm{R}$, and $\mathrm{R}$ reflects the fluctuation and gap during the low season and peak season. A comparative analysis will also be carried out herein on the seasonal intensity indexes of inbound tourism in Hainan from 2002 to 2016. Simultaneously, in terms of the research on the inbound tourism during the low season and peak season, Su Peng (2010) has calculated the monthly average indexes and divided the inbound tourism into low season and peak season by using the inbound tourism data in Hainan from 2002 to 2008. However, the data from 2002 to 2008 was out of date, and the data from 2002 to 2016 will be used herein to explore and discuss the new changes in the inbound tourism during the low season and peak season in Hainan.

In terms of spatial structure, the geographical concentration index is a key indicator reflecting the degree of concentration of inbound tourist flows in the tourist destination. It is generally believed that the closer the geographical concentration index $\mathrm{G}$ is to 100 , the more concentrated the tourist source regions will be, and the smaller the geographical concentration index is, the more scattered the tourist source regions will be. In addition, the Gini coefficient (Zhang Yujuan and Zhao Dingtao, 2008) [21] and the gravity model (Sun Gennian, 2008) [22] are also used to research the changes in the spatial structure of inbound tourism, but the application of geographic concentration index is more mature. There have been analysis on the geographical concentration index of inbound tourism across the country and in certain provinces, such as Yao Yunxia (2016) [23], Feng Yuanyuan (2016) [24], Yuan Xiaoyu (2017) [25] and Su Peng (2010). However, they neglected the influence of the number of tourist source regions on the degree of concentration, and Zhu Qinfu (2011) improved the traditional geographical concentration index, introduced the geographic concentration index evenly distributed completely, calculated the difference between the traditional geographical concentration index $G$ and the geographical concentration index evenly distributed completely, then measured the concentration degree[26] of tourists using the ratio of the difference and the completely even geographic concentration index, and this verified method could scientifically and intuitively reflect the degree of concentration of tourists after the demonstration, and the topic also adopted this indicator.

The above research on the spatial and temporal structure of inbound tourism provides a useful theoretical basis and methodological reference for the analysis on the spatial and temporal structure of inbound tourism in Hainan. After collecting the latest data, the present text calculates the seasonal intensity index, monthly average index and deviating geographical concentration index, and conducts a more complete research on the evolution of the spatial and temporal structure of the inbound tourism in Hainan in order to grasp the laws.

\section{INDICATORS OF THE EVOLUTION OF TEMPORAL SPATIAL AND STRUCTURES OF INBOUND TOURISM}

\section{A. Time dimension}

\section{1) Seasonal intensity index}

The seasonal intensity index can reflect the seasonal change situations in a specific tourism market. The formula is as follows:

$$
\mathrm{R}=\sqrt{\sum_{\mathrm{i}=1}^{12}\left(X_{i}-8.33 \%\right)^{2} / 12}
$$

The $\mathrm{R}$ in the formula (1) represents the seasonal intensity index of the inbound tourist source market calculated monthly, which ranges from 0 to 0.265 . The larger the $R$ is, the more significant the fluctuation during the low season and peak season will be, which is unfavorable to the operation of tourism enterprises; The smaller the $\mathrm{R}$ value is, the smaller the difference between the low season and peak season will be, which is conducive to the stable operation of tourism enterprises. $\mathrm{X}_{\mathrm{i}}$ is the proportion of inbound overnight tourists in Hainan during the ith month in the total inbound overnight tourist volume during the whole year, and 12 in the formula (1) represents 12 months in one year.

\section{2) Monthly average index}

To clarify the low season, shoulder season and peak season of inbound tourism, the commonly used indicator representing the seasonal changes is the monthly average index in the process of division. The formula is as follows:

$$
m_{\mathbf{i}}=\overline{\mathbf{m}_{i}} / \bar{m}
$$

In formula (2), $\mathrm{m}_{\mathrm{i}}^{\prime}$ is the monthly average index in the ith month, $\overline{\mathbf{m}_{\mathbf{i}}}$ is the average number of inbound tourist volume in the ith month for many years, $\mathrm{i}=1,2,3 \ldots 12 ; \overline{\mathrm{m}}$ is the average value of the inbound tourist volume in all months, and the monthly average index is measured by $100 \%$.

\section{B. Spatial dimension}

The traditional geographical concentration index formula is as follows:

$$
\mathrm{G}=100 \times \sqrt{\sum_{i=1}^{n}\left(X_{i} / T\right)^{2}}
$$

In formula (3), $\mathrm{G}$ is the tourist generating region concentration index, $\mathrm{n}$ is the number of tourist generating regions, $\mathrm{T}$ is the total volume of inbound tourists at the tourism destination, and $\mathrm{X}_{\mathrm{i}}$ is the number of tourists at the ith tourist generating region. The closer the $\mathrm{G}$ is to 100 , the more concentrated the tourist generating regions will be, and the smaller the $G$ is, the more scattered the tourist generating regions will be. For tourism destinations, the $G$ value should not be too large or too small. If the $\mathrm{G}$ value is too large, the tourist source markets will be too concentrated, and the drastic changes in major tourist generating regions will affect the stable development of tourism destinations; If the $G$ value is too small, the tourist source market will be too scattered, which will be not conducive to the determination of target markets and concentrated development and may easily cause high cost of market development. Simultaneously, G value is affected by 
the balance of tourist distribution and the number of tourist generating regions. Zhu Qinfu (2011) revised the traditional geographical concentration index, firstly calculated the concentration index $\overline{\mathrm{G}}$ under the complete even circumstance of tourist generating regions:

$$
\overline{\mathrm{G}}=100 \times \sqrt{\sum_{i=1}^{n}(1 / n)^{2}}
$$

Then he obtained the difference $\Delta \mathrm{G}$ between the index $\mathrm{G}$ in the traditional geographical concentration indexes and the $\overline{\mathbf{G}}$ value:

$$
\Delta \mathrm{G}=100 \times\left[\sqrt{\sum_{i=1}^{n}\left(X_{i} / T\right)^{2}}-\sqrt{\sum_{i=1}^{n}(1 / n)^{2}}\right]
$$

The ratio of $\Delta G$ and $G$ can be used to reflect the tourist source concentration degree, and the value $\mathrm{G}^{\prime}$ is called as the deviating geographical concentration index. The larger the value is, the higher the concentration degree of tourist sources will be, and on the contrary, the lower the concentration degree of the tourist sources will be. $\mathrm{G}^{\prime}$ is as follows:

$$
\mathrm{G}^{\prime}=(\Delta G / \bar{G}) \times 100
$$

III. QUANTITATIVE ANALYSIS ON THE EVOLUTION OF SPATIAL AND TEMPORAL STRUCTURE OF INBOUND TOURISM IN HAINAN

\section{A. Evolution of the temporal structure of inbound tourism in Hainan}

1) Seasonal intensity index of inbound tourism in Hainan

Through data collection, the number of inbound tourists in each month in Hainan from 2002 to 2016 is summarized in Table 1.

TABLE I. VOLUME OF INBOUND OVERNIGHT TOURISTS IN HAINAN FROM 2002 TO 2016 (10000 PERSONS)

\begin{tabular}{cccccccccccccccc}
$\begin{array}{c}\text { Kear } \\
\text { Month }\end{array}$ & 2002 & 2003 & 2004 & 2005 & 2006 & 2007 & 2008 & 2009 & 2010 & 2011 & 2012 & 2013 & 2014 & 2015 & 2016 \\
\hline January & 3.02 & 3.32 & 2.96 & 3.64 & 5.93 & 10.40 & 10.33 & 5.27 & 5.39 & 6.65 & 6.66 & 7.17 & 7.83 & 4.84 & 6.35 \\
\hline February & 4.19 & 3.71 & 3.09 & 3.08 & 5.41 & 5.04 & 6.15 & 4.84 & 4.87 & 4.89 & 6.52 & 4.01 & 4.82 & 2.80 & 4.30 \\
\hline March & 3.87 & 3.98 & 2.61 & 3.08 & 4.16 & 6.91 & 7.94 & 5.48 & 6.42 & 7.41 & 7.65 & 8.67 & 6.51 & 4.31 & 6.68 \\
\hline April & 3.23 & 0.75 & 2.67 & 3.86 & 6.15 & 5.64 & 5.85 & 6.81 & 7.14 & 8.28 & 8.52 & 10.57 & 6.15 & 6.47 & 5.91 \\
\hline May & 2.76 & 0.24 & 1.80 & 3.19 & 4.66 & 4.39 & 5.48 & 4.27 & 5.66 & 5.77 & 5.34 & 5.53 & 5.01 & 5.35 & 4.97 \\
\hline June & 2.49 & 0.33 & 1.94 & 2.76 & 4.11 & 4.75 & 4.71 & 2.93 & 4.78 & 5.23 & 4.59 & 4.43 & 4.72 & 4.73 & 4.83 \\
\hline July & 3.14 & 1.24 & 2.42 & 2.81 & 4.16 & 6.15 & 4.68 & 3.26 & 4.52 & 5.02 & 6.58 & 4.21 & 4.53 & 4.24 & 5.62 \\
\hline August & 2.71 & 2.50 & 2.17 & 3.87 & 4.48 & 6.25 & 5.38 & 4.92 & 5.61 & 5.72 & 5.71 & 5.33 & 4.93 & 5.28 & 5.60 \\
\hline September & 2.27 & 1.80 & 1.79 & 2.69 & 3.97 & 4.51 & 4.17 & 3.09 & 4.29 & 4.69 & 5.04 & 4.01 & 4.69 & 4.28 & 5.02 \\
\hline October & 3.12 & 2.79 & 1.93 & 3.50 & 5.34 & 5.02 & 6.77 & 3.80 & 4.97 & 5.61 & 5.57 & 5.68 & 5.60 & 5.63 & 7.25 \\
\hline November & 3.28 & 3.27 & 3.35 & 4.06 & 5.35 & 7.10 & 6.42 & 4.80 & 5.91 & 11.50 & 8.65 & 7.56 & 5.09 & 6.11 & 7.99 \\
\hline December & 4.72 & 4.28 & 3.94 & 5.08 & 7.95 & 9.15 & 8.11 & 5.66 & 6.75 & 10.54 & 10.73 & 8.05 & 6.23 & 6.81 & 10.37 \\
\hline Total & 38.8 & 28.21 & 30.67 & 41.62 & 61.67 & 75.31 & 75.99 & 55.13 & 66.31 & 81.31 & 81.56 & 75.22 & 66.11 & 60.85 & 74.89 \\
\hline
\end{tabular}

The seasonal intensity index $\mathrm{R}$ can be calculated based on

Table 1 and Formula (1), as shown in Fig. 1.

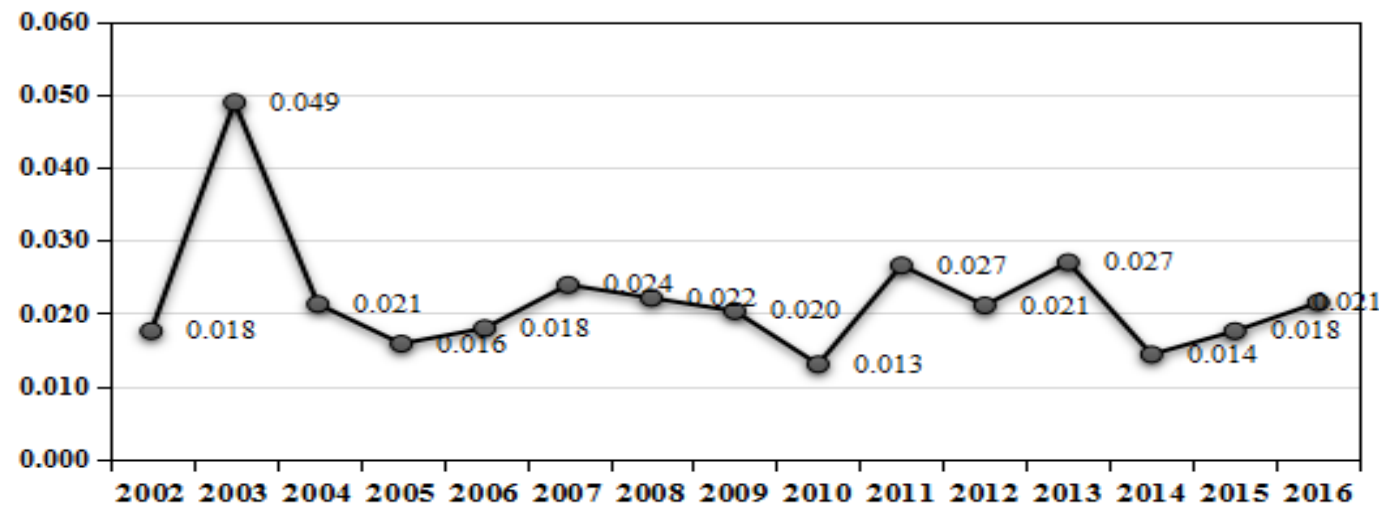

Fig. I. Seasonal Intensity Index of Inbound Tourism in Hainan Province from 2002 to 2016 
It can be seen from Fig. 1 that the seasonal intensity index of inbound tourism in Hainan from 2002 to 2016 is in a fluctuation process. The mean value of the seasonal intensity index during this period is 0.0219 , and the years in which the seasonal intensity indexes are significantly higher than this mean value include 2003, 2007, 2008, 2011 and 2013. The differences are significant in inbound tourism during the low season and peak season in Hainan in these years; The years in which the seasonal intensity indexes are significantly lower than the mean value include 2002, 2005, 2006, 2010, 2014 and
2015, and the seasonal characteristics of the inbound tourism during these periods are relatively stable.

2) Monthly average index of inbound tourism in Hainan and division of the low season and peak season

All monthly average indexes of inbound tourist volume in Hainan from 2002 to 2016 can be calculated based on the original data in Table 1, as shown in Fig. 2.

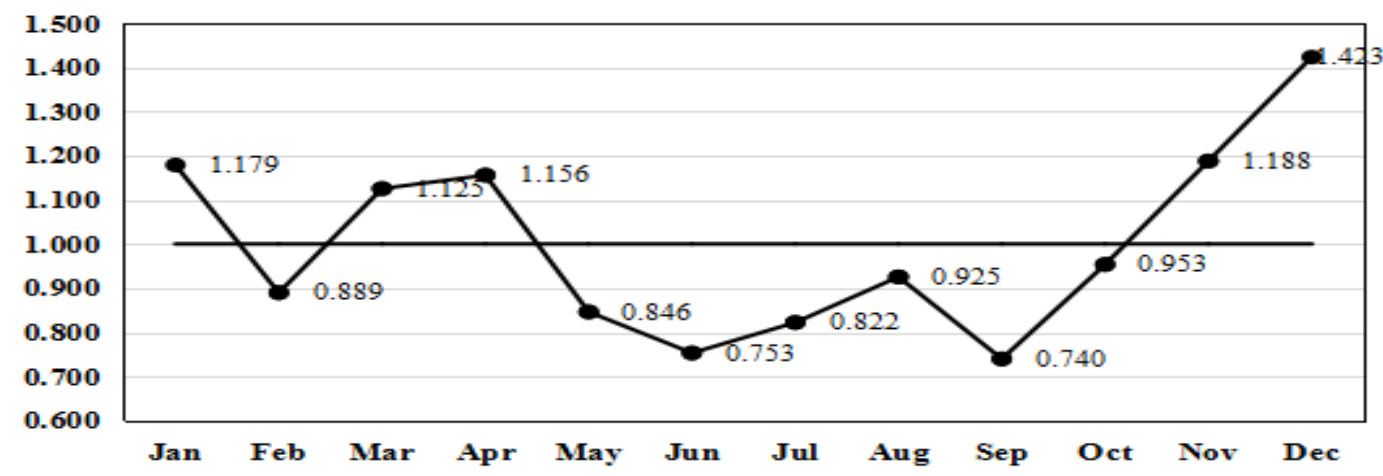

Fig. II. Monthly average index of inbound tourism in Hainan from 2002 to 2016

The mean value of monthly average indexes is $100 \%$, taking $\alpha=5 \%$. When $\mathrm{m}_{\mathrm{i}} \leq 100 \%$ - $\alpha$, the month will be the low season; When $100 \%-\alpha \leq \mathrm{m}_{\mathrm{i}} \leq 100 \%+\alpha$, the month will be the shoulder season; When $\mathrm{m}_{\mathrm{i}} \geq 100 \%+\alpha$, it will be the peak tourism season. The results in Fig. 2 show that October is the shoulder season; January, March, April, November, and December are peak seasons; February, May, June, July, August, and September are low seasons. In Su Peng's (2010) research, April is the shoulder season. In recent years, with the holding of Asian Boao Forum and the implementation of the minor vacation system, there will be a small peak in April for the inbound tourism in Hainan.

\section{B. Evolution of spatial structure of inbound tourism in Hainan}

The volume of overnight tourists from various tourist Generating regions for inbound tourism in Hainan from 2008 to 2016 is as shown in Table 2.

TABLE II. VOLUME OF OVERNIGHT TOURISTS FROM VARIOUS TOURIST GENERATING REGIONS FOR INBOUND TOURISM IN HAINAN FROM 2008 TO 2016 (10000 PERSONS)

\begin{tabular}{|c|c|c|c|c|c|c|c|c|c|}
\hline $\begin{array}{l}\text { Year } \\
\text { Tourist Generating } \\
\text { Region }\end{array}$ & 2008 & 2009 & 2010 & 2011 & 2012 & 2013 & 2014 & 2015 & 2016 \\
\hline Japan & 3.6704 & 2.7481 & 2.4786 & 2.134 & 1.6969 & 1.1009 & 0.9929 & 1.0004 & 0.9284 \\
\hline Korea & 12.7126 & 2.3807 & 3.1737 & 2.6223 & 1.6053 & 2.7357 & 1.8245 & 3.8495 & 6.4138 \\
\hline Mongolia & 0.0377 & 0.0568 & 0.0924 & 0.1464 & 0.2101 & 0.324 & 0.267 & 0.2922 & 0.2237 \\
\hline Indonesia & 0.2833 & 0.2805 & 0.3902 & 0.6088 & 0.7707 & 0.51 & 0.6483 & 0.4306 & 0.4779 \\
\hline Malaysia & 3.3167 & 2.1625 & 2.7544 & 2.2202 & 2.6624 & 2.5589 & 2.2399 & 1.8313 & 4.8877 \\
\hline Philippines & 0.1846 & 0.1626 & 0.3025 & 0.4521 & 0.2559 & 0.2506 & 0.1745 & 0.2173 & 0.2371 \\
\hline Singapore & 3.4007 & 2.782 & 4.7555 & 5.9082 & 6.9446 & 4.479 & 3.9601 & 3.3954 & 3.6224 \\
\hline Thailand & 0.5604 & 0.332 & 0.5051 & 0.6185 & 0.7293 & 0.7104 & 0.5467 & 0.8037 & 1.2956 \\
\hline India & 0.2304 & 0.1489 & 0.2417 & 0.4081 & 0.2264 & 0.1701 & 0.2263 & 0.2224 & 0.2499 \\
\hline Vietnam & 0.0513 & 0.0699 & 0.1434 & 0.0902 & 0.0871 & 0.0556 & 0.0688 & 0.087 & 0.4778 \\
\hline Myanmar & 0.0035 & 0.0017 & 0.0136 & 0.0141 & 0.0306 & 0.0218 & 0.0293 & 0.024 & 0.0594 \\
\hline North Korea & 0.1704 & 0.2145 & 0.0374 & 0.0415 & 0.0705 & 0.1041 & 0.0686 & 0.0852 & 0.0717 \\
\hline Pakistan & 0.0233 & 0.0219 & 0.0207 & 0.0223 & 0.032 & 0.0448 & 0.0728 & 0.0395 & 0.0534 \\
\hline
\end{tabular}


Table II, cont

\begin{tabular}{cccccccccccc}
\hline United Kingdom & 1.0421 & 0.7065 & 0.6397 & 0.8359 & 0.5722 & 0.6608 & 0.6906 & 0.6699 & 0.6504 \\
\hline France & 0.6986 & 0.6542 & 0.8138 & 0.8292 & 0.6216 & 0.6347 & 0.5495 & 0.5622 & 0.6437 \\
\hline Germany & 1.3479 & 1.201 & 1.7127 & 1.5484 & 1.0438 & 1.0378 & 0.9548 & 0.961 & 1.0024 \\
\hline Italy & 0.2974 & 0.2675 & 0.3193 & 0.3241 & 0.2663 & 0.2934 & 0.2574 & 0.3225 & 0.2692 \\
\hline Swiss & 0.1487 & 0.1661 & 0.31 & 0.2911 & 0.1628 & 0.1564 & 0.1415 & 0.1363 & 0.1387 \\
\hline Sweden & 0.2773 & 0.2103 & 0.2632 & 0.3063 & 0.2266 & 0.1968 & 0.1782 & 0.1987 & 0.209 \\
\hline Russia & 17.4537 & 7.9723 & 14.8411 & 22.7557 & 19.196 & 12.4888 & 9.3319 & 3.7446 & 8.0956 \\
\hline Spain & 0.1372 & 0.1246 & 0.1549 & 0.1393 & 0.0945 & 0.1242 & 0.126 & 0.1217 & 0.1524 \\
\hline United States & 2.1949 & 1.6567 & 2.2375 & 2.8582 & 2.1137 & 2.319 & 2.2791 & 2.3162 & 2.6599 \\
\hline Canada & 0.666 & 0.5719 & 0.793 & 0.9254 & 0.7246 & 0.9278 & 0.9072 & 0.8831 & 0.9889 \\
\hline Australia & 0.7009 & 0.6096 & 0.7327 & 0.8592 & 0.6871 & 0.7685 & 0.8033 & 0.7266 & 0.7568 \\
\hline New Zealand & 0.111 & 0.0757 & 0.1074 & 0.115 & 0.1493 & 0.1095 & 0.1423 & 0.1346 & 0.2484 \\
\hline Hong Kong & 14.37 & 12.18 & 11.33 & 13.62 & 11.51 & 10.39 & 10.79 & 11.87 & 13.2 \\
\hline Macao & 2.45 & 0.56 & 0.79 & 1.13 & 0.78 & 0.76 & 1.19 & 1.06 & 1.11 \\
\hline Taiwan & 7.98 & 5.2 & 6.81 & 10.54 & 17.77 & 14.44 & 12.01 & 12.32 & 13.6 \\
\hline Others & 23.409 & 11.6315 & 9.5455 & 9.0955 & 10.3197 & 17.2664 & 14.6685 & 12.5341 & 12.1758 \\
\hline $\begin{array}{c}\text { Total throughout } \\
\text { the year }\end{array}$ & 97.93 & 55.15 & 66.31 & 81.46 & 81.56 & 75.64 & 66.14 & 60.84 & 74.9 \\
\hline & & & & & & & \\
\hline
\end{tabular}

b. Source: Official Website of Hainan Provincial Tourism Commission, Statistical Yearbook of Hainan Province

The geographical concentration index of inbound tourism in Hainan from 2008 to 2016 can be calculated based on Formula (6), as shown in Table 3.

TABLE III. GEOGRAPHICAL CONCENTRATION INDEX OF INBOUND TOURISM IN HAINAN FROM 2008 TO 2016

\begin{tabular}{|c|c|c|c|c|c|c|c|c|c|}
\hline $\begin{array}{c}\text { Year } \\
\text { Index }\end{array}$ & 2008 & 2009 & 2010 & 2011 & 2012 & 2013 & 2014 & 2015 & 2016 \\
\hline $\mathrm{G}^{\prime}$ & 101.02 & 96.86 & 89.46 & 105.33 & 108.10 & 103.42 & 99.23 & 98.95 & 85.58 \\
\hline
\end{tabular}

In order to compare the relative changes in the geographical concentration indexes, the following results can be obtained from Table 3: the mean value of the geographical concentration indexes from 2008 to 2012 is 98.66 , and the geographical concentration indexes in 2009, 2010 and 2016 is smaller than the mean value through comparison. The concentration degree of the tourist generating regions in these years is relatively low and the tourists are more scattered; the geographical concentration indexes in 2014 and 2015 are slightly higher than the mean value; And the geographical concentration indexes in 2008, 2011, 2012 and 2013 are significantly higher than the mean value, and the concentration degree of the tourist generating regions in these years is relatively high. The analysis on the major tourist generating regions shows that the more significant decline in proportion of tourists from Russia, Japan, South Korea, and Macao was a major cause of the lower geographical concentration index in 2016. Simultaneously, the proportion in Taiwan, Malaysia, Thailand, Singapore, Vietnam and other tourist generating regions is slightly increased. The geographical concentration index in Hainan from 2000 to 2007 calculated by Su Peng (2010) based on the traditional geographical concentration index is declined year by year, and the degree of decline is relatively significant. However, there is a fluctuation among the geographical concentration indexes from 2008 to 2016 calculated by deviating geographical concentration indexes as adopted in the text, and the degree of change is relatively limited.

\section{CONCLUSION}

The inbound tourism market in Hainan was once slumped after the global financial crisis in 2008. The market scale of tourist generating regions such as Russia, Japan and South Korea was declined significantly and the recovery degree is limited at present; the tourist generating regions such as Taiwan, Southeast Asia shows a steady growth trend. The development pertinence of inbound tourism in Hainan in the future should be promoted, the dependence on a few major tourist generating regions should be reduced, and the publicity and promotion of emerging tourist generating regions should be appropriately expanded. The change laws of the low and peak seasons should be used, and the tourism activities and marketing activities that attract tourists from different tourist generating regions should be organized to stabilize the market fluctuations in the low and peak seasons, reduce the pressure on the tourism supply and tourism carrying capacity during the 
low and peak seasons and achieve a healthy and prosperous development of inbound tourism.

\section{ACKNOWLEDGMENT}

CLC Number: F590 Document Code: A Article No.:

Fund Program: A Scientific Research Program of Colleges and Universities in Hainan Province: "Research on Spatial and Temporal Structure, Influencing Factors and Precision Development of Inbound Tourism in Hainan" (No.: Hnky 2018-64).

About the author: BAO Fuyuan (1982-), male, born in Luoyang, Henan, a lecturer, master, and research the tourism market management, etc.

\section{REFERENCES}

[1] Baron R. Seasonality in Tourism-A Guide to the Analysis of Seasonality and Trends for Policy Making [M].London: The Economist Intelligence Unit Ltd, 1975, 1-5.

[2] Mark A, Bonn H. Seasonal variation of coastal resort visitor: Hilton Head Island. [J].Journal of Travel Research, 1992, 31(1):50-55

[3] Muzaffer U, Daniel RF, Joseph TO. Geographic and seasonal variation in the concentration of travel in the United States [J].Journal of Travel Research, 1994, (32):61-64.

[4] Donald G, PA. Responses of family businesses to extreme seasonality in demand: the case of Born holm, Denmark [J].Tourism Management, 2004, (25):17-30.

[5] Daniel M, Donald F. Basic characteristics of the fall tourism market [J].Tourism Management, 2007, (28):491-504.

[6] Erdogan K, Galip A. An analysis of seasonality in monthly per person tourist spending in Turkish in bound tourism from a market segmentation perspective [J].Tourism Management, 2007, (28):227-237.

[7] Felix C, Christine L. Spectral analysis of seasonality in tourism demand [J].Mathematics and Computers in Simulation, 2011, 81(7):1409-1418.

[8] Christine A, Martin SW. Tourism demand forecasting models: Choice of appropriate variable to represent tourists' cost of living [J].Tourism Management, 1987, 8(3):233-246.

[9] Bao Jigang and Chu Yifang. Tourism Geography [M]. Higher Education Press, 1999. (In Chinese)

[10] He Xiaorong. An Inquiry into the Means to Balance the Seasonal Consumption of China's Tourism Market [J]. Tourism Science, 2001, (1) 30-32. (In Chinese)

[11] Zhang Jie, Du Jinkang, Zhou Yinkang, Zhang Siyan and Pan Bing. Spatial Structure of Tourist Source Areas for the Naturally Scenic Sightseeing Places: A Case Study of Jiuzhaigou [J]. Acta Geographica Sinica, 1999, (4): 71-78. (In Chinese)
[12] Lu Lin, Xuan Guofu, Zhang Jinhe, Yang Xiaozhong and Wang Degen. An Approach to Seasonality of Tourist Flows Between Coastland Resorts and Mountain Resorts: Examples of Sanya, Beihai, Mt. Putuo, Mt. Huangshan and Mt. Jiuhua [J]. Acta Geographica Sinica, 2002, (6):731-740. (In Chinese)

[13] Zhong Jing, Zhang Jie, Li Donghe, Lu Song, Zhao Yong and Chen Youjun. A Comparative Research on Seasonality Characteristics of Tourist Flows to the Historic Culture Village (Town)-Examples of Xidi and Zhouzhuang [J]. Human Geography, 2007, (4): 68-71. (In Chinese)

[14] Chai Shousheng and Qiu Wen. A Study on Temporal and Spatial Structure of Inbound Tourism Market in Qingdao and Its Development Trend [J]. Journal of Ocean University of China (Social Sciences Edition), 2007, (5):80-83. (In Chinese)

[15] Zhong Jing. A Study on the Spatial and Temporal Characteristics of Foreign Market for Inbound Tourism in China [J]. Inquiry into Economic Issues, 2008, (9):122-126. (In Chinese)

[16] Jiang Guohua and Li Jian. Modeling and Analyzing Shanghai Inbound Tourism Demand [J]. Journal of Central South University of Forestry \& Technology (Social Sciences), 2016, 10(5): 90-94. (In Chinese)

[17] Liao Qin. A Study on the Changes of Inbound Tourism Market in Shanghai and Its Influencing Factors [D]. Shanghai Normal University, 2013. (In Chinese)

[18] Su Peng. A Study on Spatial and Temporal Structure of Inbound Tourism in Hainan and Its Optimization [D]. Hainan University, 2010. (In Chinese)

[19] Chen Yun and Tian Liang. Seasonal Characteristics and Control Measures of Inbound Tourism in Hainan [J]. Human Geography, 2013, 28(4): 140-143. (In Chinese)

[20] Wang Qin'an and Zhang Lihui. Analysis on Time Sequence Difference Characteristics and Spatial Pattern Evolution of Inbound Tourism in China [J]. Statistics and Decision, 2017, (14):130-134. (In Chinese)

[21] Sun Gennian, Yang Ren and Yao Hong. Study on the Regional Structure Change of Chinese Inbound Tourism Based on the Gravity Model [J]. Journal of Arid Land Resources and Environment, 2008, (7):150-157. (In Chinese)

[22] Yao Yunxia, Guan Weihua and Li Zai. An Analysis of the Temporalspatial Evolution of Inbound Tourist Flow of Jiangsu Province and its Influencing Factors [J]. Tourism Science, 2016, 30(5):52-62. (In Chinese)

[23] Feng Yuanyuan. A Study on Temporal and Spatial Evolution and Development Trend of Inbound Tourism Market in Shandong Province [D]. Ludong University, 2016. (In Chinese)

[24] Yuan Xiaoyu and Tang Wenxia. Study on the Spatial Structure of Inbound Tourist Source Market in Xinjiang [J]. Journal of Harbin University of Commerce (Social Science Edition), 2017, (1):114-121. (In Chinese)

[25] Zhu Qinfu et al. An Improvement of Evaluating Method on Tourist Concentration Degree with Geographic Concentration Index [J]. Tourism Tribune, 2011, 26(4):26-29. (In Chinese) 